\title{
Workflow Design Optimization Based on Software Design
}

\author{
Wei Jiayuan, Guo Cong, and Zhou Quan
}

\begin{abstract}
Recently, the work flow management system has been widely used in the research and development project management and office automation fields. Demand for business department workflow system is increasing. In the process design for business department, some specific rules are usually contained, which vary with the variation of management. Thus with even a small modification is the rules the process design document must be re-built, It will be more costly if this is realized by modifying back-end code. To improve the expansibility of workflow system, a method is presented in this paper by abstracting business rules, custom vocabularies and rules to achieve matrix-form rule management. This method simplifies the complex logic implemented in the process design, and visualizes the realization of business logic through the business rule designer, which is more understandable in the business perspective.
\end{abstract}

Index Terms - Business rules, management, rules engine, workflow.

\section{INTRODUCTION}

With the continuous development of enterprise scale, internal work management more complex, transaction processes tend to be cross-regional and timeliness have higher demand. Information office is inevitable trend to improve business efficiency and reduce the cost. Workflow management system is adapted to the development of a modern enterprise, convenient and secure electronic file transfer platform based network environment, improve office efficiency, paperless office, and promote the process of information and enhance overall competitiveness [1].

Workflow is partially or entirely of business processes applications automate by computer, you can make documents, information or tasks automatically according to some predefined rules between multiple participants, in order to achieve one business goal [2], or promote achieve this goal. Different with traditional management software, it is concerned that the process of how to shorten the idle time to improve business processing capabilities and focus on the real meaning of value-added services for business on [3].

Workflow management software widely used in practical work, Specifically in key business processes can be responsible for order processing, quote processing, procurement processing, contract review, customer call

Manuscript received March 3, 2015; revised November 26, 2015. This work was supported in part by National Natural Science Foundation of China under Grant No. 61372175 and the Natural Key Laboratory Foundation of China under Grant No.9140C530403130C53192.

Wei Jiayuan and Zhou Quan are with the National Key Laboratory of Science and Technology on space Microwave, China Academy of Space Technology, Xi'an, 710100, China (e-mail: weijy@ cast504.com).

Guo Cong is with Hangzhou Hollysys Automation Co., Ltd. Xi'an Branch, 710000, China (e-mail: guocong9527@163.com). handling, supply chain management, etc.; on the administration can provide travel request, overtime application, leave requests, car application, apply a variety of office supplies, purchase applications and other daily weekly circulation of all the original manual handling administrative forms; In personnel management, you can arrange for staff training, performance appraisal, job changes processing [4], employee records and information for effective treatment; in the financial aspects associated with it can process the payment request, receivables, daily reimbursement, travel reimbursement, budget and plan to apply; in the customer service, which provides customer information management, customer complaints, request processing, service management, and other aspects of management; in particular services can be implemented ISO series corresponding processes, quality management corresponding processes, product data information management, customs processing trade companies, logistics companies and other cargo tracking processing tasks circulation through the form step by step manual [5], [6].

Workflow is based on the electronic file transfer platform network environment, through the network platform, internal organization staff can span time and place to work, with all kinds of electronic forms of information transfer business, the implementation of the process of processing, tracking, query, statistics and other operations.

\section{NECESSITY OF BUSINESS RULES STRIPPED FROM THE PROCESS DESIGN}

Because of widely used the workflow. Business process demand workflow design process has short cycle, less code, easy upgrade and maintenance features. Process design cost lots time in the implement business rules. In traditional, the business rules achieve by adding branches and activities. This usually increases the complexity of the process. And when business rules change, we must modify the process.

This article will attempt to strip out rules from the business process, designed to simplify the process. In addition, the Web-based structure of the workflow system can even design rules by opening the relevant authority, directly to the demand side of the business sector to achieve [7]. Making process designers from the complex business rules to get out, when business rules change again in the future, only need to modify the rule parameters of matrix management, without having to modify the process [8], [9].

To analyze the implementation of business rules designer, we need to define the following terms set forth:

Workflow [10]: means "part or the whole of the business process in computer environment automation." It is an abstraction and broadly described of business rules between the respective process steps. 
Business Rules [11]: practices, management statutes, regulations, industry standards and business-related, etc., can be called business rules.

Rules Engine: evolved by the inference engine, is an embedded component in the application, to achieve business decisions will be separated from the application code out and use predefined semantics module written business decisions.

\section{WORKFLOW DEVELOPMENT PLATFORM INTEGRATED RULES ENGINE}

Schematic Rule Engine is showing in Fig. 1.

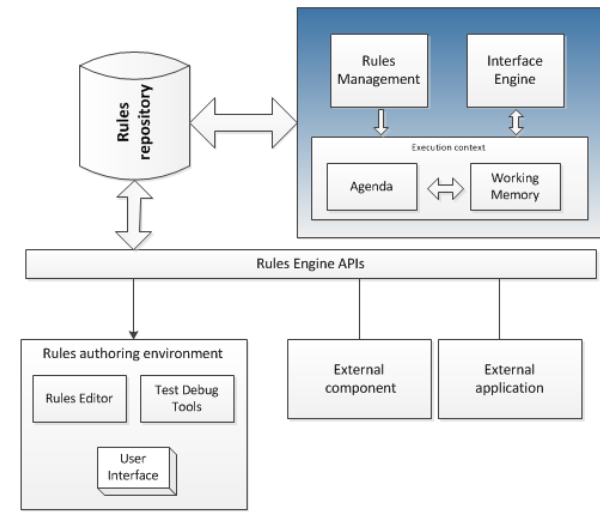

Fig. 1. Architecture of rule engine.

\section{A. Glossary}

A new business rules need to define the rules related to the variable name.

Vocabulary type and data model item type of business rules attribute correspondence;

Business rules parameter types have three ways

\begin{tabular}{|c|c|c|}
\hline Parameter Type & \multicolumn{2}{|l|}{ Explanation } \\
\hline IN & \multicolumn{2}{|c|}{ Parameter input from outside } \\
\hline OUT & \multicolumn{2}{|c|}{ Parameters returned by the business rules } \\
\hline INOUT & \multicolumn{2}{|c|}{$\begin{array}{l}\text { Bidirectional mode, after the external input from the } \\
\text { outside and then back to business rules }\end{array}$} \\
\hline \multicolumn{3}{|c|}{ TABLE II: EXPLANATION OF RULE TYPE } \\
\hline Rule Type & Name & Explanation \\
\hline Script & $\begin{array}{l}\text { Scripts } \\
\text { rules }\end{array}$ & $\begin{array}{l}\text { Scripts decision table, you can freely } \\
\text { enter the formula in the matrix, the } \\
\text { rules engine will compute ranks } \\
\text { conditions are met the cell formulas; }\end{array}$ \\
\hline Selective Array & $\begin{array}{l}\text { Selection } \\
\text { rules }\end{array}$ & $\begin{array}{l}\text { Select the decision table, pre-set } \\
\text { rules and select personnel ranks, and } \\
\text { then check the condition of the cell } \\
\text { based on business logic, the system } \\
\text { will satisfy the conditions of the cell } \\
\text { participants returned. }\end{array}$ \\
\hline Sorted Array & Sorted rules & $\begin{array}{l}\text { Select the decision table, pre-set } \\
\text { rules and choose who ranks in the } \\
\text { cell needs to be reviewed in the order } \\
\text { entered digits, the system will be in } \\
\text { numerical order staff will review } \\
\text { series. }\end{array}$ \\
\hline
\end{tabular}

\section{B. Rule Definition}

Rule contains three types: script, selection rules, sorted rules. They are three different mechanisms, and therefore need to define script rules sorted rules and selection rules parser, the following table illustrates the difference between the various rules.

\section{RULES ENGINE ALGORITHMS INTRODUCED}

Most of the rules engine algorithms products, mostly from RETE algorithm and its variants proposed in 1979 by Dr. Charles Forgy, RETE algorithm is one of the most efficient inference algorithm Forward-Chaining.

\section{A. The Basic Idea}

RETE algorithm is a model for efficient production system matching algorithm. In a production system, the data is processed, called working memory, the rules for determining the two-part LHS (left-hand-side) and RHS (right hand side), respectively, the premise and conclusion. The main flow can be divided into the following steps:

1) Match: LHS parts conform to find a collection of working memory

2) Conflict resolution: to elect a rule conditions are met

3) Act: execution RHS content

4) Return (1)

RETE algorithm process Match of the major improvements by building a network to match.

\section{B. A Detailed Description of the Algorithm}

RETE network is divided into two parts, alpha and beta network. As shown in Fig. 2:

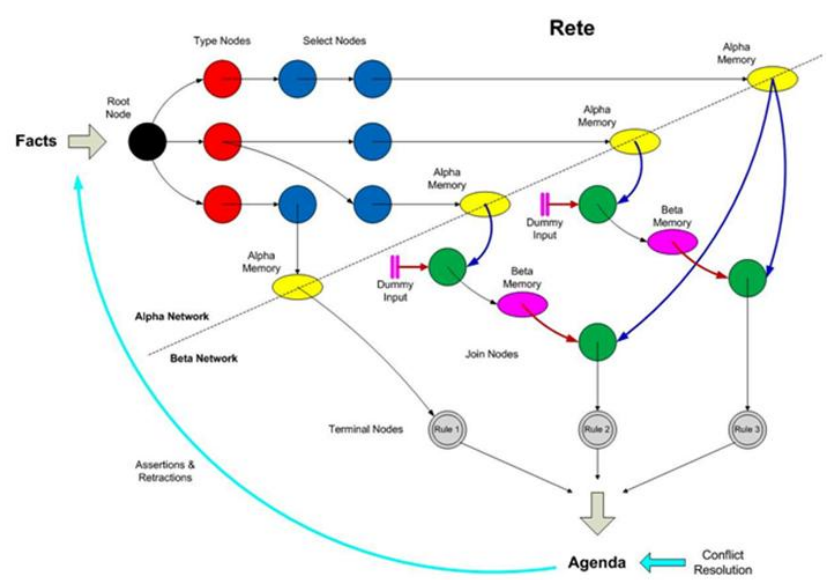

Fig. 2. RETE network.

1) Alpha Network: a Filter working memory, find the collection in line with the rules of each model to generate alpha memory (meet set the pattern). There are two types of nodes, nodes filter type and other conditions of the filter node (I think these two are set in accordance with the needs, it does not necessarily require two nodes).

2) Beta network: There are two types of nodes Beta Memory and Join Node. Upon completion of the collection of the former main storage join. The latter includes two input ports. Respectively, need to match two sets of input from the combined work done Join node is transmitted to the next node [12], [13].

\section{Matching Process Description}

1) Import fact need to be addressed to the facts set. 
2) If the facts are not empty, select a fact for processing. Otherwise, stop the matching process.

3) Select the first node runs (when set to establish a network), through which the node is the next node alpha network, until well into the alpha memory alpha network. Otherwise, skip to the next one judge paths.

4) The result is added to the alpha memory beta memory, and the fact that the existence of the condition if not Terminal node, another input is detected in the collection, is performed to meet the join, move to the next beta memory repeatedly performed (3). If no other input set of the fact that the condition is satisfied, return to (2). If the node is terminal node executed and added to the facts in the ACT.

\section{COMPUTATIONAL EXAMPLES AND ANALYSIS}

In order to illustrate abstract business rules to simplify the process plays an important role, for example, following the purchase requisition review matrix:

TABLE III: PURCHASE REQUISITION REVIEW MATRIX

\begin{tabular}{|c|c|c|c|c|}
\hline \multirow[b]{2}{*}{ Participants } & \multicolumn{2}{|c|}{ Office Supplies } & \multicolumn{2}{|c|}{ Production equipment } \\
\hline & $\begin{array}{l}\text { Purchase } \\
\text { Amount } \\
<2000\end{array}$ & $\begin{array}{l}\text { Purchase } \\
\text { Amount } \\
>=2000\end{array}$ & $\begin{array}{l}\text { Purchase } \\
\text { Amount } \\
<10000\end{array}$ & $\begin{array}{l}\text { Purchase } \\
\text { Amount } \\
>=10000\end{array}$ \\
\hline $\begin{array}{l}\text { Business } \\
\text { executives }\end{array}$ & $\sqrt{ }$ & $\sqrt{ }$ & $\sqrt{ }$ & \\
\hline $\begin{array}{l}\text { Department } \\
\text { Director }\end{array}$ & $\sqrt{ }$ & & $\sqrt{ }$ & $\sqrt{ }$ \\
\hline $\begin{array}{l}\text { Chief Financial } \\
\text { Officer }\end{array}$ & & $\sqrt{ }$ & & $\sqrt{ }$ \\
\hline General manager & & $\sqrt{ }$ & & $\sqrt{ }$ \\
\hline
\end{tabular}

The matrix, based on the type of [purchase], [amount], require different personnel for review, if implemented in the process design, process logic will be complicated. At this point you can use the business rules defined in the rule, the business logic implemented in the graphical definition of business rules, more in line with the business perspective to understand.

\section{Define the column:}

Column information is generally used to edit the conditions to support multi-level table headers way.

\section{Definition line:}

Rows and columns of information similar to the information set, is generally used to set the participant or a script expression.

TABLE IV: FINAL ASSIGNMENT OF PARTICIPANTS

\begin{tabular}{lllll}
\hline \hline & \multicolumn{2}{l}{ Office Supplies } & \multicolumn{2}{l}{ Production equipment } \\
\cline { 2 - 5 } Participants & $\begin{array}{l}\text { Purchase } \\
\text { Amount } \\
<2000\end{array}$ & $\begin{array}{l}\text { Purchase } \\
\text { Amount } \\
>=2000\end{array}$ & $\begin{array}{l}\text { Purchase } \\
\text { Amount } \\
<10000\end{array}$ & $\begin{array}{l}\text { Purchase } \\
\text { Amount } \\
>=10000\end{array}$ \\
\hline $\begin{array}{l}\text { Business } \\
\text { executives } \\
\begin{array}{l}\text { Department } \\
\text { Director } \\
\text { Chief Financial } \\
\text { Officer }\end{array}\end{array}$ & 1 & 1 & 1 & 1 \\
\begin{tabular}{l} 
General manager \\
\hline \hline
\end{tabular} & 2 & 2 & 2 & 2 \\
\hline
\end{tabular}

The collation is all cells need to perform a continuous connective valuation, it will be the final assignment of participants to the specified participant type vocabulary, such as the Table IV:

\section{Said the implications for:}

When the purchase of office supplies when type is

Amount is less than 2000, the needs of business executives, audit director;

Amount is greater than or equal to 2,000, the needs of business executives, Chief Financial Officer, General Manager of the audit;

When the purchase is the production of the type of device

The amount of less than 10,000, the needs of business executives, audit director;

When the amount is greater than equal to 10,000 , and the needs of business executives, department director, Chief Financial Officer for review;

\section{CONCLUSIONS}

This paper introduces the workflow in the enterprise wide application of information technology group context, in order to improve efficiency, while the market requirements of the business rules change frequently, in order to quickly and cost updates, business people should be able to directly manage IT system rules without require developers to participate. This paper presents a business rules engine, workflow platform to introduce the idea. Design to achieve a separation of business rules and processes designed to simplify the process design. After introducing the basic arithmetic rules engine after example demonstrates the matrix rules governing the actual optimization process. However, based on the rules of inference engine in the realization of business rules have some limitations. Future research should continue in terms of script-based rules engine, thereby improving the utilization rate of business rules.

\section{ACKNOWLEDGMENT}

The research work was supported by National Natural Science Foundation of China under Grant No. 61372175 and the Natural Key Laboratory Foundation of China under Grant No.9140C530403130C53192.

\section{REFERENCES}

[1] Z. Muehlen, "Organizational management in workflow applications - Issues and perspectives," Information Technology and Management, vol. 5, no. 4, pp. 271-294, 2004.

[2] D. Georgakopoulos, M. F. Hornick, and A. P. Sheth, "An overview of workflow management: from process modeling to workflow automation infrastructure," Distributed and Parallel Databases, vol. 3, no. 2, pp. 119-153, 1995.

[3] G. Alonso, D. Agrawal, and E. A. Abbadi, "Functionality and limitations of current workflow management systems," IEEE Expert, vol. 2, no. 5, 1997

[4] G. Alonso and H.-J. Schek, "Research issues in large workflow management systems. Proceedings of NSF workshop on workflow and process automation in information systems," State-of-the-Art and Future Directions, 1996.

[5] D. V. Antonellis, M. Melchiori, and P. Plebani, "An approach to web service compatibility in cooperative processes," in Proc. 2003 Symposium on Applications and the Internet Workshops (SAINT'03 Workshops), pp. 95-100, 2003.

[6] G. Canals, C. Godart, and F. Charoy, "Approach to support cooperation in software developments," IEEE Proceedings in Software Engineering, vol. 145, no. 1, pp. 79-84, 1998 
[7] P. Senkul and I. Toroslu, "An architecture for workflow scheduling under resource allocation constraints," Information Systems, vol. 30 , no. 5, pp. 399-422, 2005.

[8] E. Deelman, D. Gannon, M. Shields, and I. Taylor, "Workflows and e-science: an overview of workflow system features and capabilities," Future Generation Computer Systems, pp. 126-132, 2008.

[9] W. Chen and E. Deelman, "WorkflowSim: A toolkit for simulating scientific workflows in distributed environments," in Proc. 2012 IEEE 8th International Conference on eScience, pp. 145-152, 2012.

[10] S. Ferill, "Woman: logic-based workflow learning and management," IEEE transactions on systems, vol. 44, no. 6, pp: 744-756, 2014.

[11] D. Martin, M. Burstein, J. Hobbs, O. Lassila, D. McDermott, S Mcllraith, S. Narayanan, M. Paolucci, B. Parsia, T. Payne, E. Sirin, N. Srinivasan, and K. Sycara, "OWL-S: Semantic markup for web services," W3C Member Submission, November 2004.

[12] I. Horrocks, P. F. Patel-Schneider, H. Boley, S. Tabet, B.Grosof, and M Dean, "SWRl: A semantic web rule language combining owl and ruleml," W3C Member Submission, 2004.
[13] D. Grigori, F. Charoy, and C. Gobart, "Flexible data management and execution to support cooperative workflow: the coo approach," in Proc. the Third International Symposium on Cooperative Database Systems for Advanced Applications (CODAS 2001), pp. 124-131, 2001.

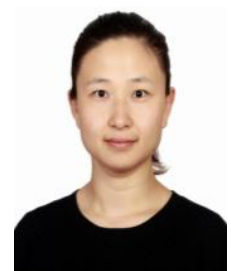

Wei Jiayuan was born in January 1988. She received her master's degree in communication and system engineering from China Academy of Space Technology in 2013. She is now with the National Key Laboratory of Science and Technology on space microwave, China Academy of Space Technology, Xi'an, 710100, China. Her research interests include digital image processing, data hiding, and automated management. 